\title{
Promotive effect of jasmonates on the senescence of detached maize leaves
}

\author{
Kuo Tung Hung \& Ching Huei Kao* \\ Department of Agronomy, National Taiwan University, Taipei, Taiwan, Republic of China ${ }^{*}$ author for \\ correspondence)
}

Received 18 July 1995; accepted 25 October 1995

Key words: ethylene, jasmonic acid, leaf senescence, methyl jasmonate, Zea mays

\begin{abstract}
Promotion of senescence of detached maize leaves by jasmonates was investigated. Senescence of detached maize leaves was promoted by linolenic acid, the precursor of biosynthesis of jasmonic acid, and retarded by inhibitors of lipoxygenase, the first enzyme in the biosynthetic pathway of jasmonic acid. Results support a role of endogenous jasmonates in the regulation of senescence of detached maize leaves. Silver thiosulfate, an inhibitor of ethylene action, was found to inhibit methyl jasmonate, linolenic acid- and abscisic acid-promoted senescence of detached maize leaves. It seems that jasmonate-promoted senescence is mediated through an increase in ethylene sensitivity in detached maize leaves.
\end{abstract}

Abbreviations: $\mathrm{ABA}=$ abscisic acid; $\mathrm{MJ}=$ methyl jasmonate; $\mathrm{STS}=$ silver thiosulfate

\section{Introduction}

Methyl jasmonate (MJ) and free acid, jasmonic acid, have been found to occur throughout the plant kingdom [11]. Leaf senescence is the sum of various physiological processes that involve the loss of chlorophyll, proteins and nucleic acids, disassembly of membrane, and alterations in gene expression program and in enzyme activities [20]. It has been shown that exogenous jasmonates promoted leaf senescence $[6,16,21]$. However, it remains to be established whether endogenous jasmonates regulate leaf senescence.

Ethylene production by $\mathrm{MJ}$ in tomato fruits has been described [9]. Chou and Kao [7] demonstrated that MJ had no effect on ethylene production in detached rice lcaves, but stimulated 1-aminocyclopropane-1-carboxylic acid-dependent ethylene production. Ethylene is also known to promote leaf senescence [2, 10, 13, 17]. Abeles et al. [1] reported that ethylene was not involved in MJ-promoted senescence of excised cucumber cotyledons. Cuello et al. [8] also demonstrated that MJ and ethylene promoted senescence of barley leaf senescence by different mechanisms.
In this study, we examined the role of endogenous jasmonates on senescence of detached maize leaves by using precursor and several inhibitors of lipoxygenase, the first enzyme in the proposed biosynthetic pathway of jasmonic acid. The possible involvement of ethylene in regulating MJ-promoted senescence of detached maize leaves was also investigated.

\section{Materials and methods}

Seedlings of maize (Zea mays cv. Taimung 1) were grown in vermiculite in a greenhouse with natural light at $30^{\circ} \mathrm{C}$ day $/ 25^{\circ} \mathrm{C}$ night for 7 days, by which time the primary leaves were fully expanded. The apical 2.5 $\mathrm{cm}$ segments were excised from the primary leaves and were placed in Petri dishes containing $15 \mathrm{~mL}$ of distilled water or test solutions and incubated at $27^{\circ} \mathrm{C}$ in the dark.

Chlorophyll was extracted and determined following the method of Wintermans and De Mots [25] after extraction in $96 \%$ ethanol. For protein determination, leaf segments were homogenized in $50 \mathrm{~m} M$ sodium phosphate buffer ( $\mathrm{pH} \mathrm{6.8)}$. The extracts were centri- 

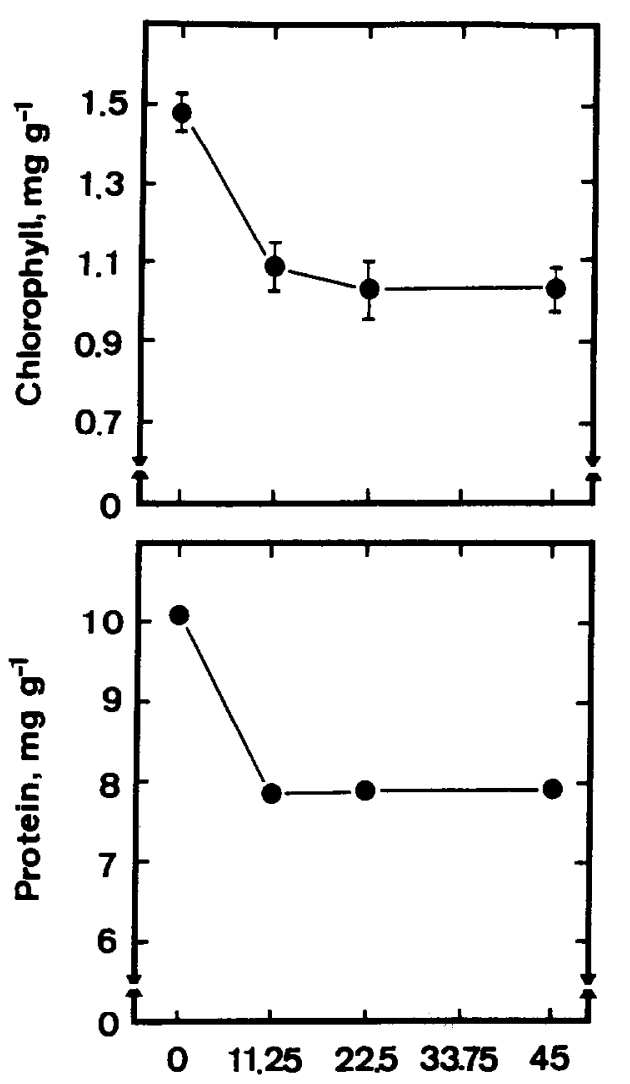

\section{MJ, $\mu \mathrm{M}$}

Figure 1. Effect of methyl jasmonate on chlorophyll and protein levels in detached maize leaves. Chlorophyll and protein levels were determined after 4 days in darkness. Bars indicate $S E(n=4)$. Only those SE larger than symbol size are shown.

fuged at $17,600 \mathrm{~g}$ for $20 \mathrm{~min}$, and the supernatant liquids were used for determination of protein by the method of Bradford [5]. Chlorophyll and protein levels were expressed as $\mathrm{mg} \mathrm{g}^{-1}$ fresh weight.

In experiments with $\mathrm{Ag}^{+}$, STS was used as a source. Leaf segments were treated with STS and test solution. A stock solution of STS was prepared by mixing equal volumes of $0.01 \mathrm{MAgNO}_{3}$ and $0.04 \mathrm{M}$ $\mathrm{Na}_{2} \mathrm{~S}_{2} \mathrm{O}_{3}[14]$.

\section{Results and discussion}

The senescence of detached maize leaves in the dark was followed by measuring the decrease of chlorophyll and protein. Figure 1 shows the effect of MJ on the levels of chlorophyll and protein in detached maize
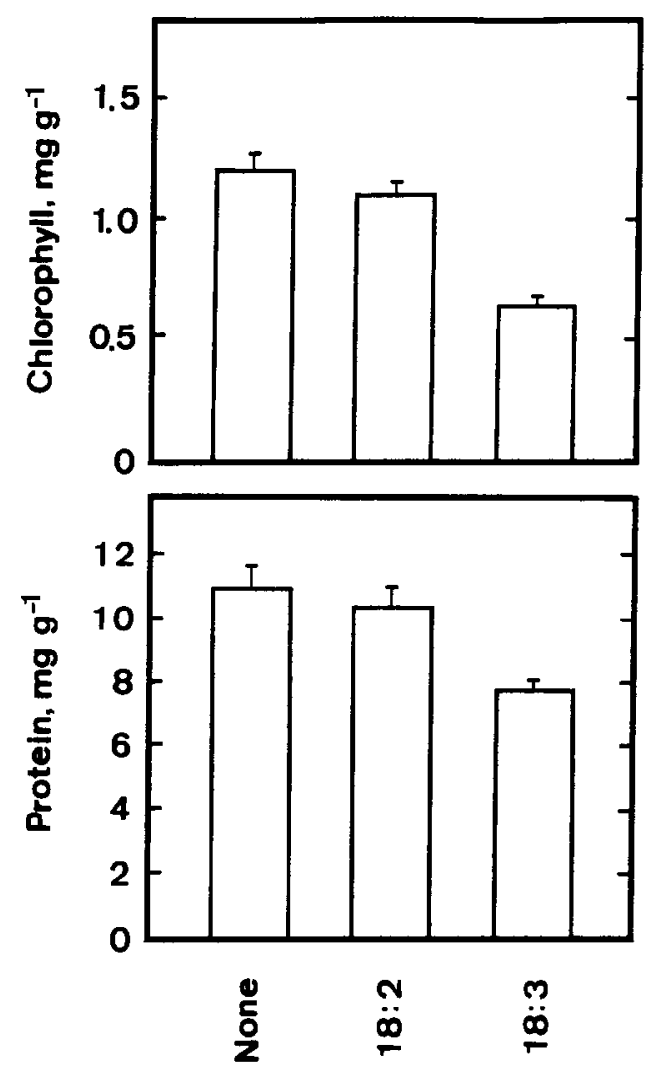

Figure 2. Effect of linoleic acid (18:2) and linolenic acid (18:3) on chlorophyll and protein levels in detached maize leaves. All treatments included $0.1 \%$ Tween 20 . Chlorophyll and protein levels were determined after 3 days in darkness. The concentration of 18:2 and $18: 3$ was $5 \mathrm{mM}$. Bars indicate $S E(n=4)$.

leaves. MJ significantly promoted the senescence of detached maize leaves. MJ concentration at $11.25 \mu \mathrm{M}$ is as effective as that at $45 \mu \mathrm{M}$ in promoting senescence of detached maize leaves.

Oxidation of linolenic acid (18:3) by lipoxygenase is the first step in the biosynthesis pathway of jasmonic acid [24]. The availability of linoleic acid (18:2), linolenic acid and several inhibitors of lipoxygenase provided the opportunity to investigate whether endogenous jasmonates regulate senescence of detached maize leaves.

If endogenous jasmonates play a role in the regulation of senescence of detached maize leaves, linolenic acid, but not linoleic acid, is expected to promote senescence, whereas lipoxygenase inhibitors are expected to retard senescence. Figure 2 shows the effect of linoleic acid and linolenic acid on the levels of chlorophyll and protein in detached maize leaves. It is clear that linolenic acid, but not linoleic acid, signifi- 

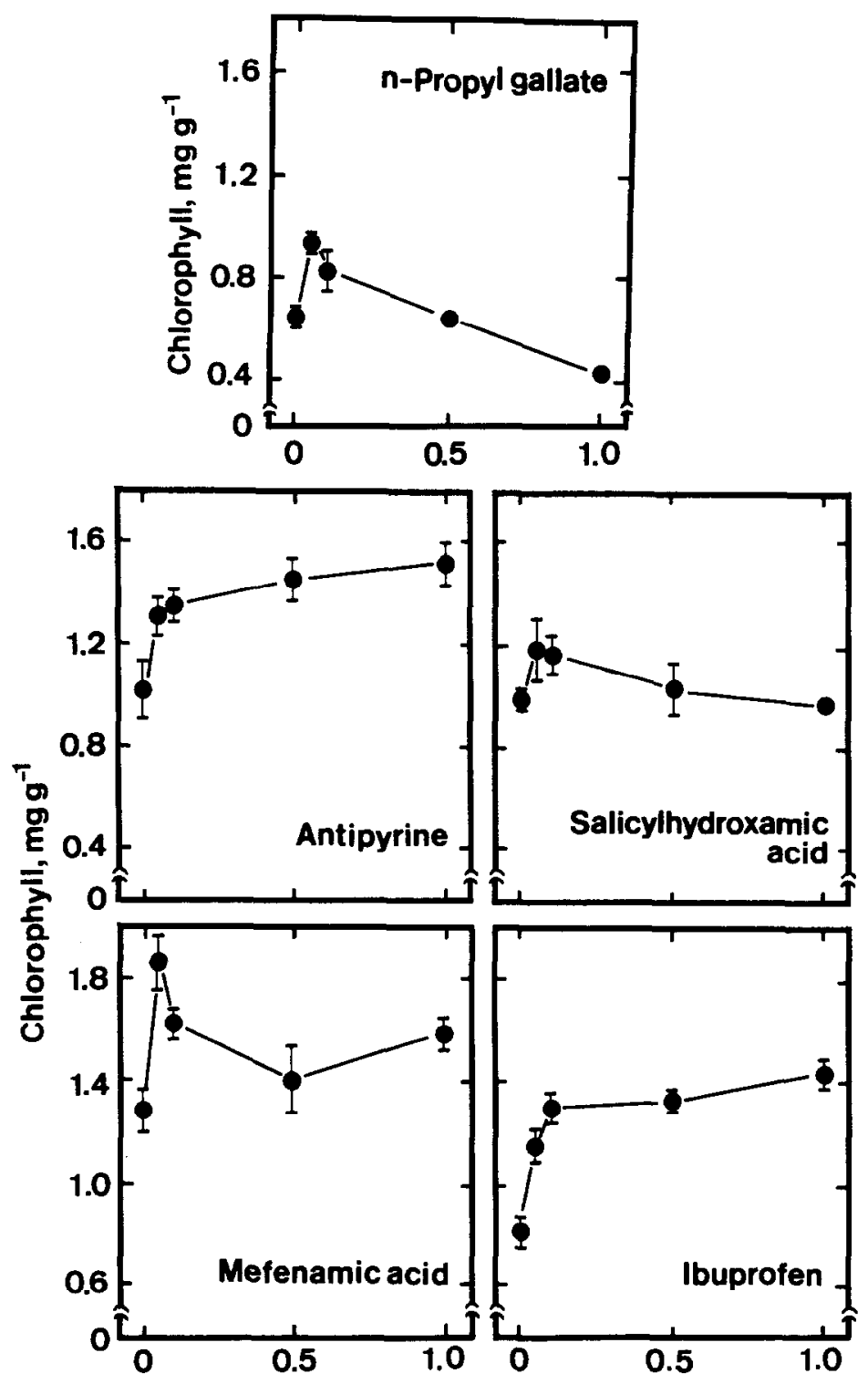

Concentration, $\mathrm{mM}$

Figure 3. Effect of lipoxygenase inhibitors on chlorophyll level in detached maize leaves. The pH of all solutions was maintained near neutrality with $0.2 \mathrm{~m} M$ potassium phosphate, $\mathrm{pH} 7.0$. Chlorophyll level was determined after 4 days in darkness. Bars indicate $S E$ ( $\mathrm{n}=4$ ). Only those SE larger than symbol size are shown.

cantly promoted senescence of detached maize leaves. However, Ueda and Kato [22] demonstrated that both linoleic acid and linolenic acid promoted senescence of oat leaves. The effect of various compounds previously shown to inhibit lipoxygenase $[15,19]$ on senescence of detached maize leaves in darkness is presented in Figures 3 and 4. All five lipoxygenase inhibitors at the appropriate concentration retarded senescence of maize leaves.

Although the inhibitors we used are diverse in their structures, there are similarities among them. We cannot rule out the possibility that the inhibitors acted 

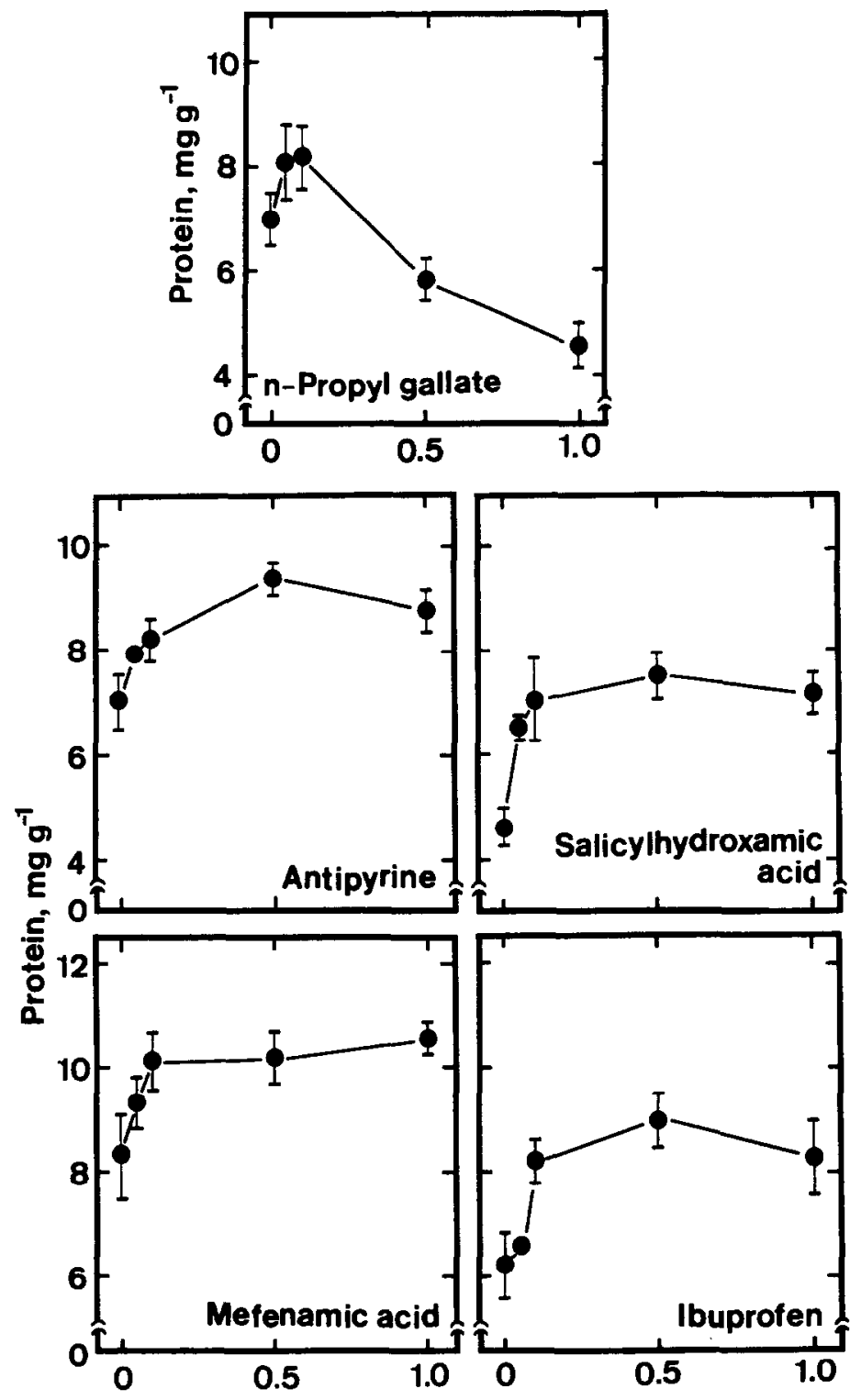

Concentration, $\mathrm{mM}$

Figure 4. Effect of lipoxygenase inhibitors on protein level in detached maize leaves. The pH of all solutions was maintained near neutrality with $0.2 \mathrm{mM}$ potassium phosphate, $\mathrm{pH}$ 7.0. Protein level was determined after 4 days in darkness. Bars indicate $S E(n=4)$. Only those SE larger than symbol size are shown.

by a mechanism other than the inhibition of lipoxygenase, although the variety of compounds tested suggests otherwise. Salicylhydroxamaic acid and npropyl gallate are chelators of divalent cations and they inhibit the alternative respiratory pathway [18]. It will be important to establish whether jasmonic acid increases during senescence of detached maize leaves and whether the lipoxygenase inhibitors block the increase in jasmonic acid level.

The results that linolenic acid, precursor of jasmonic acid biosynthesis, promoted senescence and the lipoxygenase inhibitors retarded senescence 

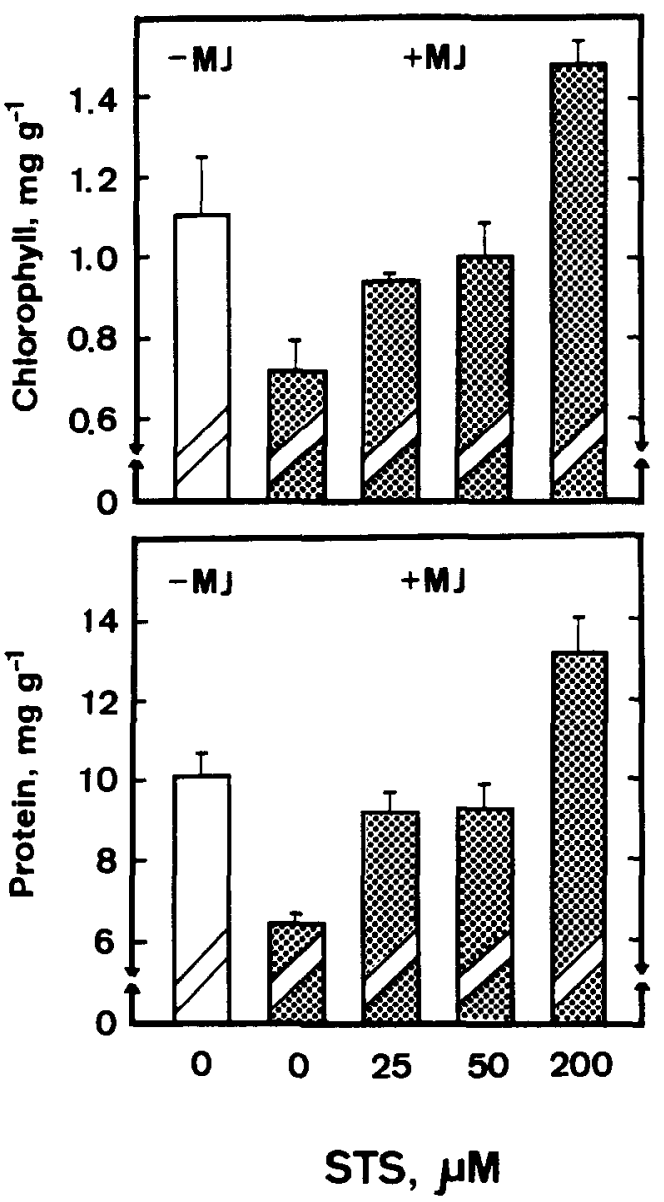

Figure 5. Effect of silver thiosulfate (STS) on methyl jasmonate (MJ)-promoted senescence of detached maize leaves. The concentration of MJ was $45 \mu \mathrm{M}$. Chlorophyll and protein levels were determined after 4 days in darkness. Bars indicate $S E(n=4)$.

support a role for endogenous jasmonic acid in regulating senescence of detached maize leaves.

Previously, we have shown that ethylene production in detached maize leaves was very low (less than $10 \mathrm{~nL} \mathrm{~g}^{-1} 24 \mathrm{~h}^{-1}$ ) and remained relatively constant during the course of senescence in darkness [12]. These results indicate that ethylene production does not play a role in regulating dark-induced senescence of detached maize leaves. If a change of ethylene level is excluded as an explanation for the senescence of detached maize leaves, a change in sensitivity to ethylene is an alternate possibility. This possibility was tested by using ethylene action inhibitor, $\mathrm{Ag}^{+}$[4]. In the present investigation, STS was used as a source of $\mathrm{Ag}^{+}$. The advantage of using STS are related to a lower free $\mathrm{Ag}^{+}$in STS solutions and a lower phytoxicity of this compound $[14,23]$. The effect of STS on MJ- and
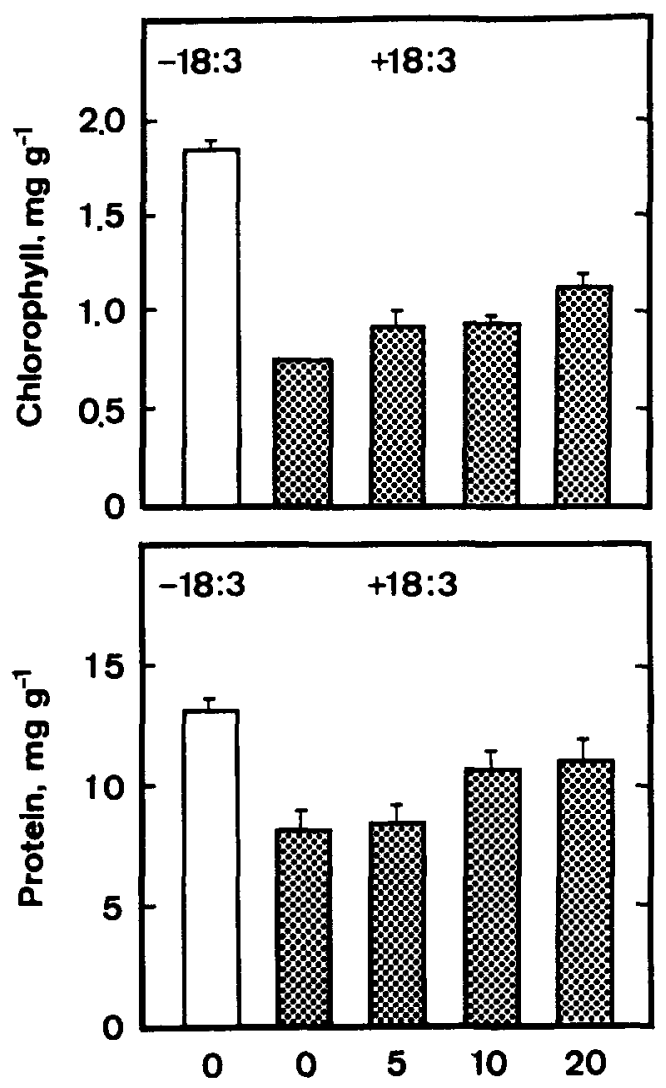

STS, $\mu \mathrm{M}$

Figure 6. Effect of silver thiosulfate (STS) on linolenic acid (18:3)-promoted senescence of detached maize leaves. The concentration of $18: 3$ was $5 \mathrm{mM}$. All treatments included $0.1 \%$ Tween 20. Chlorophyll and protein levels were determined after 4 days in darkness. Bars indicate SE $(n=4)$.

linolenic acid-promoted senescence of detached maize leaves was shown in Figures 5 and 6, respectively. STS was observed to inhibit MJ- and linolenic acidpromoted senescence of detached maize leaves. These results indicate that an increase in ethylene sensitivity is involved in regulating $\mathrm{MJ}$ - and linolenic acidpromoted senescence in detached maize leaves. Our results are in contrast to those of other workers, who showed that the action of MJ on senescence was independent of ethylene $[1,8]$. Since STS is less effective in inhibiting linolenic acid-promoted senescence of maize leaves, other mechanisms that may be involved in regulating linolenic acid-induced senescence can not be excluded. 

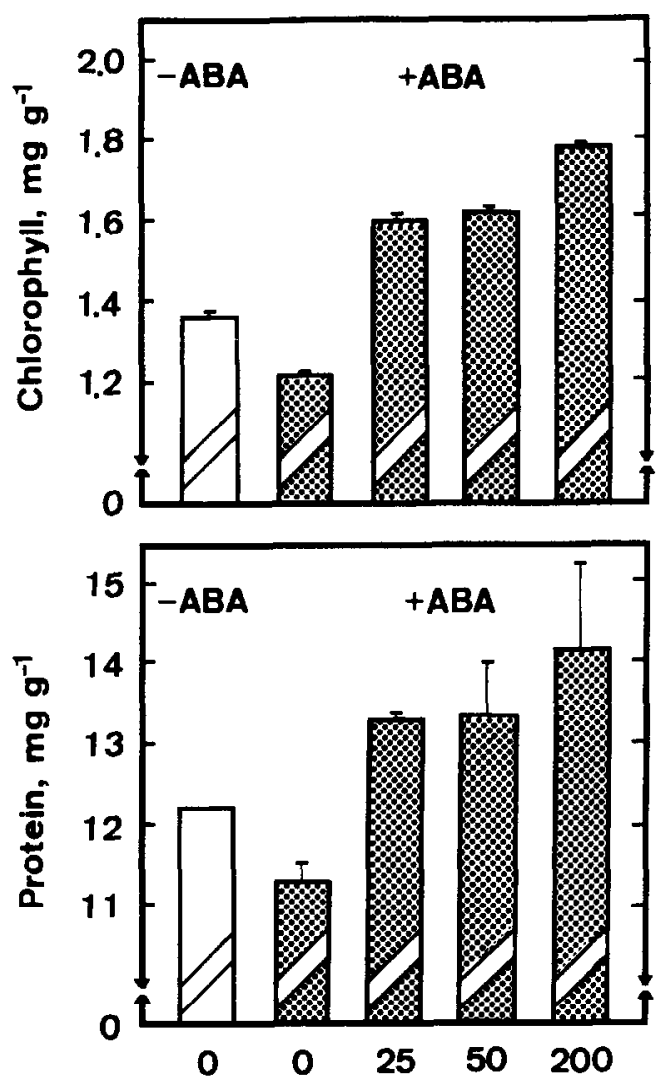

\section{STS, $\mu \mathrm{M}$}

Figure 7. Effect of silver thiosulfate (STS) on abscisic acid (ABA)-promoted senescence of detached maize leaves. The concentration of $\mathrm{ABA}$ was $45 \mu \mathrm{M}$. The $\mathrm{pH}$ of all test solutions was adjusted to 5.5 by $0.1 \mathrm{~N} \mathrm{HCl}$. Chlorophyll and protein levels were determined after 4 days in darkness. Bars indicate $S E(n=4)$.

Previously, we found that ABA promoted senescence of detached maize leaves but inhibited ethylene production [12]. We suggested, but did not prove, that $A B A$ increased tissue sensitivity to ethylene [12]. Jasmonates and ABA have both chemical and physiological similarity [3]. Thus it is of great interest to know whether the promotive response of $\mathrm{ABA}$ on senescence of detached maize leaves is also mediated through a change in ethylene sensitivity. As indicated in Figure 7, ABA-promoted senescence is indeed mediated through a change in ethylene sensitivity.

\section{Acknowledgment}

This work was supported by the Council of Agriculture, Republic of China [84 AST-2.1-FAD-27(6)].

\section{References}

1. Abeles FB, Hershberger WL and Dunn LJ (1989) Hormonal regulation, and intracellular localization of 33-KD cationic peroxidase in excised cucumber cotyledons. Plant Physiol 89: 664-668

2. Aharoni $N$ and Lieberman $M$ (1979) Ethylene as a regulator of senescence in tobacco leaf discs. Plant Physiol 64: 801-804

3. Anderson JM, Spilatro SR, Klauer SF and Franceschi VR (1989) Jasmonic acid-dependent increase in the level of vegetative storage proteins in soybean. Plant Sci 62: 45-52

4. Beyer EM Jr (1976) A potent inhibitor of ethylene action in plants. Plant Physiol 58: 268-271

5. Bradford MM (1976) A rapid and sensitive method for the quantitation of microgram quantities of protein utilizing the principle of protein-dye binding. Anal Biochem 72: 248-254

6. Chou CM and $\mathrm{Kao} \mathrm{CH}$ (1992) Methyl jasmonate, calcium, and leaf senescence in rice. Plant Physiol 99: 1693-1694

7. Chou CM and Kao CH (1992) Stimulation of 1-aminocyclopropane-1-carboxylic acid-dependent ethylene production in detached rice leaves by methyl jasmonate. Plant Sci 83: 137141

8. Cuello J, Quiles MJ, Garcia C and Sabater B (1990) Effects of light and growth substances on senescence of barley leaf segments at different developmental stages. Bot Bull Acad Sin 31: 107-111

9. Czapski J and Saniewski M (1992) Stimulation of ethylene production and ethylene-forming enzyme activity in fruits of the non-ripening nor and rin tomato mutants by methyl jasmonate. J Plant Physiol 139: 265-268

10. Gepstein S and Thimann KV (1982) The role of ethylene in the senescence of oat leaves. Plant Physiol 68: 349-354

11. Hamberg M and Gardner HW (1992) Oxylipin pathway to jasmonates: biochemistry and biological significant. Biochim Biophys Acta 1165: 1-18

12. Kao CH (1992) Role of ethylene in senescence of detached corn leaves. Chin Agron J 2: 207-212

13. Kao CH and Yang SF (1983) Role of ethylene in the senescence of detached rice leaves. Plant Physiol 73: 881-885

14. Liu J, Mukherjee I and Reid DM (1990) Adventitious rooting in hypocotyls of sunflower (Helianthus anus L.) seedlings. III. The role of ethylene. Physiol Plant 78: 268-276

15. Park TK and Polacco JC (1989) Distinct lipoxygenase species appear in the hypocotyl/radical of germinating soybean. Plant Physiol 90: 285-290

16. Parthier B (1991) Jasmonates, new regulators of plant growth and development: many facts and few hypotheses on their actions. Bot Acta 104: 446-454

17. Philosoph-Hadas S, Pesis E, Meir S, Reuveni A and Aharoni N (1989) Ethylene-enhanced senescence of leafy vegetables and fresh herbs. Acta Hortic 258: 37-45

18. Siedow JN and Girvin ME (1980) Alternative respiratory pathway. Its role in seed respiration and its inhibition by propyl gallate. Plant Physiol 65: 669-674

19. Sircar JC, Schwender CF and Johnson EA (1983) Soybean lipoxygenase inhibition by nonsteroidal antiflamatory drugs. Prostaglandins 25: 393-396 
20. Thomas H and Stoddart JL (1980) Leaf senescence. Annu Rev Plant Physiol 31: 83-111

21. Ueda J and Kato J (1982) Inhibition of cytokinin-induced plant growth by jasmonic acid and its methyl ester. Physiol Plant 54 : 249-252

22. Ueda $J$ and Kato $J$ (1982) Abscisic acid and $C_{18}$-unsaturated fatty acids as senescence-promoting substances from oat plants. J Plant Growth Regul 1: 195-203
23. Veen $\mathrm{H}$ (1983) Silver thiosulfate: an experimental tool in plant science. Sci Hortic 20: 21 1-224

24. Vick BA and Zimmerman DC (1984) The biosynthesis of jasmonic acid by several plant species. Plant Physiol 75: 458461

25. Wintermans JFGM and De Mots A (1965) Spectrophotometric characteristics of chlorophylls $\mathrm{a}$ and $\mathrm{b}$ and their pheophytins in ethanol. Biochim Biophys Acta 109: 448-453 